\title{
On non-progressive being
}

Article

Accepted Version

Schmerling, S. F. and Krivochen, D. G. (2018) On nonprogressive being. Canadian Journal of Linguistics/Revue canadienne de linguistique, 63 (1). pp. 112-119. ISSN 17101115 doi: https://doi.org/10.1017/cnj.2017.38 Available at https://centaur.reading.ac.uk/77308/

It is advisable to refer to the publisher's version if you intend to cite from the work. See Guidance on citing.

To link to this article DOI: http://dx.doi.org/10.1017/cnj.2017.38

Publisher: Cambridge University Press

All outputs in CentAUR are protected by Intellectual Property Rights law, including copyright law. Copyright and IPR is retained by the creators or other copyright holders. Terms and conditions for use of this material are defined in the End User Agreement.

www.reading.ac.uk/centaur

\section{CentAUR}

Central Archive at the University of Reading

Reading's research outputs online 
On non-progressive being

Susan F. Schmerling

Austin, Texas

susan.schmerling@gmail.com

Diego Gabriel Krivochen

University of Reading, CINN

diegokrivochen@hotmail.com

1. Introduction

Some years ago, one of the authors of this squib was working in a large organization with many layers of management. It often happened that a manager who usually performed certain functions was unavailable to do so, and those functions were performed by a so-called backup, who was authorized to perform them in the manager's absence. It was common for a backup performing such a function to say a sentence like (1) to other employees, and those other employees might speak of the occasion using a sentence like (2):

(1) I'm being Mary today.

(2) Sue is being Mary today.

In the kind of situation described, employees who were not performing these managerial functions accepted sentences like (1) and (2) and understood them to be communicating the propositions conveyed by (3):

(3) Mary has authorized \{me / Sue \} to perform functions in her absence that she normally performs.

Sentences (1) and (2) could be- -and were- taken to be truthful. It was possible for them to be taken this way precisely because it was understood that they meant that Sue was acting in Mary's stead. That is, it was understood that in sentences (1) and (2) the subject, informally 
termed a backup, as indicated above, was functioning as what might be referred to legalistically as a proxy for the NP immediately following being.

Sentences like (1) and (2) have the appearance of progressives. We will argue, however, that the interpretation of such sentences, where the subject is understood as a proxy for the NP immediately following being, does not follow from our understanding of the semantics of progressive utterances generally, such as that discussed in Dowty (1979) and much subsequent work (see Landman, 1992; Portner, 2011, and references cited there). We will argue, in fact, that despite the presence of -ing in these sentences, -ing does not contribute to a progressive interpretation, and we will propose an alternative account that is not grounded in aspect. This account takes as its point of departure two types of sentences of the form $N P_{1} B E$ being $N P_{2}$, where $N P_{2}$ is a proper name: (a) cases in which $N_{2}$ is formally distinct from $\mathrm{NP}_{1}$, and (b) cases in which $\mathrm{NP}_{2}$ is formally identical to $\mathrm{NP}_{1}$; we will suggest extensions of our analysis of these sentences to sentences with indefinite complement NPs, as well as APs.

Section 2 has three subsections. In section 2.1 we look at sentences like (1) and (2) in more detail. Then in section 2.2 we examine another class of sentences that at first glance seem quite unlike sentences (1) and (2)—sentences like John is (just) being John—but which, we will argue, are understood in the same manner as they are. This section includes our proposed formal account of the two sentence types we are concentrating on, an account that reflects our position that we are dealing here with something other than true progressives, the occurrence of -ing notwithstanding. Our alternative account makes use not of progressive semantics but rather of a novel operator rho $(\rho)$ in semantic representations, which narrows down the reference of the NPs occurring in these sentences but in a way that does not involve aspect. Our rho-based account has a critical pragmatic component, and section 2.3 looks at the pragmatic factors that are at work in speakers' understanding of the sentences in sections 
1 and 2. Section 3 takes a look at sentences like John is being a genius or John is being brilliant, in which the complement of BE being is an indefinite NP or an AP. Section 4 is a conclusion.

\section{Two kinds of NP complements of BE being}

This section includes our proposed formal account of the sentence types presented in the Introduction

2.1 Stand-in and role-playing sentences

Sentences (1) and (2), on the reading that concerns us here, are understood as discussing proxies - generally known informally as backups —in the hierarchical organizations in which they are used. A critical property of these sentences is they must almost obligatorily involve a form of $B E$ being; it is generally not enough for them to refer to situations that are temporary, as in (4) and (5), which were suggested to us by an anonymous reviewer. Our informants who have worked in bureaucracies are generally uncomfortable with these and prefer interpretations where the speaker, Sue, and Mary are playing parts in a play: ${ }^{1}$

(4) I will be Mary today.

(5) Sue should be Mary today.

The near-complete restriction to BE being of what we will call stand-in sentences (because, as we will argue, the subject is understood as a stand-in for the NP following being) can be

*We would like to thank Andy Rogers and two anonymous CJL reviewers for comments that made this a better paper. All shortcomings are our own.

${ }^{1}$ It must also be understood that, contrary to another reviewer suggestion, in sentences like (1) and (2) Mary remains department manager; Sue is authorized for some limited time, such as a day, to perform some of her functions in her absence, but, crucially, she does not become manager. 
understood using concepts from Montague (1973), “The Proper Treatment of Quantification in Ordinary English” (henceforth $P T Q$ ): we analyse the definite NP serving as the subject of the sentence, as well as the NP immediately following BE being-Mary in sentences (1) and (2) —as picking out sets of properties, which we can think of as those that make up Sue and Mary the people. Let us denote the property set for what we will call the fundamental Sue as $\lambda \mathrm{PP}\left\{\wedge_{s}\right\}$, and for the fundamental Mary as $\lambda \mathrm{PP}\{\wedge m\}$; still following Montague (1973), we abbreviate these as $s^{*}$ and $m^{*}$ respectively. What we are calling the fundamental person in each case is basic, not standing in for any other person. Recall now the rho operator mentioned in section 1: rho applies to the interpretation of an NP immediately following $B E$ being and picks out a subset of the properties making up the interpretation of the subject. ${ }^{2}$ As we will see shortly, the specific subset that is picked out in a given case is determined contextually.

We now propose that the interpretation of a sentence like (2) includes (6), which we assume is in the scope of a time adjunct like today, as in (2) itself, or a time that is readily understood in the context of utterance:

(6) $=\left(s^{*}, \rho\left(m^{*}\right)\right)$

(6) states that the property set of the subject (here Sue) is equal to a subset of the referent of the NP in predicate position (Mary). In the case of sentence (2), (6) gives us that Sue's property set includes a subset of Mary’s property set, for example, a set containing the

\footnotetext{
${ }^{2}$ Formally,
} $\rho(\lambda \mathrm{PP}\{x\}) \subseteq(\lambda \mathrm{QQ}\{x\})$, where $\mathrm{x}$ is a contextually determined variable of type $\langle s, e>$, the type of functions from reference points to individuals. 
property of being responsible for approving sick leaves. The membership of this subset is determined contextually; we will return to the question of contextual determination shortly. ${ }^{3}$

As we have mentioned, sentences like (1) and (2)—and also (4) and (5)—can be understood in a way that involves not proxies but rather roles that the subject is or will be playing. It is easiest to imagine this role-playing understanding in a situation where the speaker and Sue are members of the cast of a play, and where the subjects of these sentences are to perform roles in that play that are designated by the NPs that are the complements of $B E$ being. This role-playing understanding of sentences like (1) and (2) is not limited to plays, however. Suppose that Mary has a habit of making guesses about what is happening on the fifth floor of the building housing her department. Suppose now that Sue makes a guess about what is happening on that floor. One could comment on this resemblance between Sue’s behaviour and Mary’s by uttering sentence (2), Sue is being Mary. This role-playing use to which the sentences under discussion here and in section 1 can be put argues against any analysis that would make this or the proxy understanding an integral part of their meaning. However, the multiplicity of ways in which sentences like (1) and (2) can be understood, in appropriate contexts, shows that they are more versatile than one might expect if they were simple expressions of extensional identity.

2.2 Instantiation sentences and a formal analysis

${ }^{3}$ One may ask if (6) is also in the scope of a progressive operator, such as Dowty’s (1979: 134) PROG. We believe that the evidence for the presence of a PROG operator in (1) and (2) is meagre. Note that alternatives to BE being sentences do not occur in the progressive:

(i) I’m Mary’s backup today.

(ii) Sue is Mary’s backup today. 
Something similar to the interpretation of sentences (1) and (2) is in evidence in a sentence like (7):

(7) Dick Nixon was (just) being Dick Nixon. ${ }^{4}$

Imagine (7) uttered in the context of a report of Nixon saying "I am not a crook.” To see how (7) is perhaps surprisingly similar in meaning to sentence (2), consider how it differs from a sentence like (8), which is of course a tautology:

(8) Dick Nixon was Dick Nixon.

A tautology like (8) may imply that we all know what Nixon was like (, namely...). (Compare Boys will be boys.) But the interpretation of (7) is crucially different from that of sentence (8). The meaning we are discussing for a sentence like (7) does not depend on speakers' engaging in cooperative behaviour in the way that a conversational implicature like that engendered by (8) does (see our discussion of Grice’s Cooperative Principle in section 2.3 below). And unlike (8) with an associated conversational implicature, (7) does not require a tautological reading for its interpretation—and indeed it does not make use of one: sentence (7) is not a tautology in the first place.

A rough paraphrase of (7) is that Nixon was displaying properties that helped give him his distinctive character. We might think of the token of Dick Nixon that functions as the subject of sentence (7) as referring to former U.S. president Richard Milhouse Nixon as he famously appeared on American television on November 17, 1973, and said, "I am not a

\footnotetext{
${ }^{4}$ Haj Ross (p.c.) has brought to our attention the possibility of a sentence like (i):

(i) Nixon was (just) being himself.

Our judgments are unclear about whether (i) is or can be equivalent to (7). If the two sentences can indeed be interpreted as equivalent, this is of course a problem for any theory that requires anaphors and non-anaphors to be in complementary distribution.
} 
crook.” This Nixon was an instantiation of the fundamental Nixon, just as, legalistically, Sue in sentence (2) is functioning as an instantiation of her manager Mary. One of the members of the property set of the fundamental Nixon was the property of appearing shifty. The stand-in Nixon — the denotation of the subject NP—shared this property with the fundamental Nixon, so that having a shifty appearance was a member both of the fundamental Nixon's property set and of the contextually determined subset of that set.

Using the notation we introduced in section 2.1, we propose (9) as the semantic representation of sentence (7):

(9) $=\left(\rho\left(n^{*}\right),\left(n^{*}\right)\right)$

To see how (9) works as it does, it will be helpful, first, to summarize the various linguistic and non-linguistic entities that we are dealing with. Such a summary is given in (10-14):

(10) Richard Nixon, a U.S. president, who is (was) an individual

(11) Richard Nixon, an English NP

(12) $n^{*}$, a PTQ-style translation of the English NP Nixon into PTQ’s Intensional Logic (IL), equivalent to $\lambda \mathrm{PP}\{\wedge n\}$

(13) $\rho$, a 1-place operator that takes an NP-type extension as input and returns another NPtype extension as output, namely, a contextually determined subset of the set of properties denoted by the input (see fn. 2). In the case at hand, we have that $\rho\left(n^{*}\right)$ is a contextually determined subset of the set of properties denoted by $n^{*}$.

(14) =, a 2-place operator taking expressions of like syntactic categories as input and yielding an expression as output that denotes extensional identity of those two inputs. Before we get to what " $=\left(\rho\left(n^{*}\right),\left(n^{*}\right)\right)$ " means, we have to review the more general assumptions we are making about translations of English into IL and about their interpretations in a model. First, we assume that sentences are interpreted relative to the Cartesian coordinates (or other coordinate system) of sets of possible worlds, sets of times 
(which we take to be intervals), set of speakers, set of places, and so on. This is the only place in our analysis where intervals come into play. Since we are making this assumption about reference points for all sentences, we can dispense with the particulars in specific cases, notably where intervals are concerned.

Our second assumption is that the rho operator applies to expressions of IL, not to individuals or to any of the denotata of the English expressions we may be dealing with, nor to the results of applying formal operations to those denotata. Specifically, we assume that the denotation of “ $n *$ ” is the set of Nixon's properties, not Nixon himself: Nixon was a person, not a set. The denotation of " $\rho\left(n^{*}\right)$ ” is a contextually determined subset of "( $\left.n^{*}\right)$ ” (at the time (the interval) at which the sentence is evaluated-or, rather, since this sentence is in the past tense, at a time preceding that time.)

We are now ready to look at what “= $\left(\rho\left(n^{*}\right),\left(n^{*}\right)\right)$ " denotes. It has to denote the extensional identity, within the context of a given utterance, of Nixon's property set and a contextually determined subset of his property set. This result is neither contradictory nor tautological. It is not contradictory, because the two sets $n^{*}$ and $\rho\left(n^{*}\right)$ are not mutually contradictory (recall that a set can be a subset of itself). It is not tautological, because the sets $n^{*}$ and $\rho\left(n^{*}\right)$ do not necessarily have the same members. It does not matter, in any of the foregoing, what properties the individual Nixon has, since we are dealing with operations performed on IL expressions, not on Nixon himself. Nor does anything special need to be said about an interval during which $n^{*}$ holds (or during which $\rho\left(n^{*}\right)$ holds), because those intervals will always be the intervals at which the sentences containing them are evaluated (or intervals preceding these, in the case of past-tense sentences like (7)).

When we apply these considerations to our bureaucrats Sue and Mary, we see that our analysis does not say that Sue the individual has more or fewer properties than Mary the individual. If we are dealing with $=\left(\left(s^{*}\right), \rho\left(m^{*}\right)\right)$, we see that extensional identity is 
predicated of Sue's property set and a contextually determined subset of Mary’s properties. Now it happens that in the world of bureaucracies to which our squib in part pertains, one who is a backup for a manager remains a backup for that manager only during the time in which the manager serves as such. It would be wrong to say that either our analysis or a modification of it entails that Sue has properties now that Mary has in general. At the time of the evaluation of the sentence Sue has properties that Mary has in general, within the bureaucracy in which she is employed. As indicated earlier, an example of the kind of property that Sue would have under these circumstances might be that of being responsible for approving sick leaves. It would be rare indeed for Sue to be asked to be older or younger than Mary, these not being properties over which she has control, or to buy a car like the car that Mary drives: this is where context plays a crucial role.

\subsection{Contextual determination}

We have mentioned that the particular set of properties picked out by the rho operator is contextually determined. Not just any subset of Mary's properties is relevant to the interpretation of sentence (2), and, analogously, not just any set of properties of the instantiation of Nixon is relevant to the interpretation of sentence (7). We are here making crucial use of the assumption that the speakers and listeners of these sentences are exploiting the Cooperative Principle (CP) introduced by Paul Grice (1975), according to which people make their contributions to joint interactions maximally cooperative. Such joint interactions include conversation (Grice 1975: 45, 48-49), and a special case of the CP is Grice’s Maxim of Relation, which includes (15):

(15) Be relevant.

The role played by (15) in the understanding of sentences (2) and (7) explains why a speaker encountering one of them who does not know their context of use cannot grasp their significance. 
How might the CP be at work in the interpretation of sentences (16) and (17)?

(16) Sue is being Mary today. (= (2))

(17) Dick Nixon was (just) being Dick Nixon. (= (7))

Our understanding of the membership of $\rho\left(s^{*}\right)$ as it pertains to Sue's role as Mary's backup in the context of a bureaucracy depends on numerous propositions conveyed by way of Grice’s Maxim of Relation, of which only two follow here:

- Our knowledge that Mary is absent from the department of which she is the manager or has duties that will soon require her to be absent; and

- Our knowledge that Sue is competent to handle the managerial functions that she is likely to be called upon to perform as Mary’s backup.

Our understanding of Nixon's denial that he was a crook - that is, our understanding of one member of $\rho\left(n^{*}\right)$ —depends at least on the following points, which again derive via Grice's Maxim of Relation. Here, since we are not dealing with a situation that is an everyday occurrence, the relevant propositions may seem larger in number; we list three that stand out:

- Our knowledge that Nixon had an untrustworthy demeanour;

- Our knowledge that men working for Nixon had been caught in an undercover operation at the headquarters of the opposition Democratic party; and

- Our knowledge of the discovery of an unexplained 181/2 minute gap in a subpoenaed tape recording of a private conversation between Nixon and White House Chief of Staff H. R. Haldeman.

3. Sentences with indefinite NPs and APs

The sentences we have considered so far in this squib have involved definite NPs as the complements of BE being. Yet indefinite NPs readily occur in this context, as do APs:

(18) John is being a genius!

(19) John is being brilliant! 
As with the definite NPs we have studied, these indefinite predicate modifiers hold for their subjects in limited contexts; we do not understand (18) and (19) as being equivalent to (20) and (21), respectively:

(20) John is a genius!

(21) John is brilliant!

It would appear that we need our semantics for (18) and (19) to be like that in (6) and (9) inasmuch as these modifiers must denote subsets of the sets of properties denoted by the subjects. But (18) and (19) involve existential quantification; the semantics for these sentences cannot be as straightforward as that in (6) and (9), as the latter two differ from the former two in not containing any variables.

We propose that the semantics for John is being a genius is as in (22), in which $\pi$ is a variable ranging over properties and $\Pi$ is a designated variable ranging over sets of properties. In (22), the predicate modifier is of the same type as an NP-a set of propertiesjust as it is in (6) and (9):

(22) $\exists \pi \in \Pi\left(\subseteq \rho(\Pi),\left(j^{*}\right)\right) \wedge(=(\pi$, genius $))$ or, unpacked, $\exists \pi \in \Pi(\subseteq \rho(\Pi),(\lambda \pi \pi\{\wedge j\})) \wedge(=(\pi$, genius $))$

(22) states that there is some property $\pi$ that is a member of a contextually relevant property set that is a subset of John's property set, and $\pi$ is the property of being a genius. The interpretation of John is brilliant is exactly parallel, except that brilliant appears in place of genius.

The formula in (22) does not ensure that John is a genius. This is precisely the contrast between (18) and (20), on the one hand, and between (19) and (21) on the other: in (18) (19), the speaker asserts that John is acting in the way a genius would, without asserting at the same time that the property of being a genius is inherent to John. (22) thus derives the desired reading. 


\section{Concluding remarks}

In this squib, we have proposed novel analyses of sentences of the form $N P_{1} B E$ being $X P_{2}$, both sentences in which $\mathrm{XP}_{2}$ is a proper name and sentences in which $\mathrm{XP}_{2}$ is an indefinite description or an AP. We have argued that various instances of phrases immediately following $B E$ being are not true progressives. The sentences we have studied have to do with NP reference that is restricted when compared with the reference of the same NPs in other contexts. Our conclusion is that these restrictions do not have to do with aspect; rather, we hope to have shown, they are restrictions on NP reference in which an NP refers to a subset of the set of properties that that NP denotes in other contexts. We have furthermore shown that this conclusion holds if NPs and APs immediately following BE being have NP-type meanings and if their interpretation involves quantification over properties rather than individuals.

References

Dowty, David R. 1979. Word meaning and Montague grammar. Dordrecht: Reidel.

Grice, H. Paul. 1975. Logic and conversation. In Syntax and semantics, volume 3: Speech acts, ed. Peter Cole and Jerry L. Morgan, 41-58. New York: Academic Press.

Landman, Fred. 1992. The progressive. Natural Language Semantics 1(1): 1-32.

Montague, Richard. 1973. The proper treatment of quantification in ordinary English. In Approaches to natural language, ed. Julius Moravcsik, Patrick Suppes, and Jaakko Hintikka, 221-242. Dordrecht: Reidel.

Portner, Paul. 2011. Perfect and progressive. In Semantics: An international handbook of natural language meaning, ed. Claudia Maienborn, Klaus von Heusinger, and Paul Portner. De Gruyter Mouton. 1217-1262. 